\title{
Participation in Discussion Spaces of Health Informatics in Brazil
}

\author{
Marcelo Fornazin and Luiz Antonio Joia \\ Getulio Vargas Foundation, Brazil \\ fornazin@gmail.com, luiz.joia@fgv.br
}

\begin{abstract}
This work analyses instances of discussion related to the Brazilian public policy on health information and communication technologies (ICT). Departing from a theoretical model, which relates health ICT outcomes to instances of discussion, this work aims to identify how multiple actors participate on decision-making processes regarding health ICT. Laws and norms related to discussion forums about Brazilian health system were researched. The work shows that the discourse of participation has been present since SUS (Brazilian Unified Health System) beginnings, and, in recent years, new forums have been created. Thus, this paper concludes with the importance of a coordinated work between the forums, as well as the very need of participation of multiple actors in the instances of discussions about health ICT.
\end{abstract}

Keywords: Health Information Systems, Public Policy, Informatics in Brazil's Health System.

\section{Introduction}

Over the last twenty years, countries have bet on national strategies to incorporate information and communication technologies (ICT) into health practices [1-5] and scientific literature about Health Information Systems (HIS) reports that the informatization of health is a long-term process influenced by diverse actors [1, 6-8].

This is also the case in Brazil, where the first HIS emerged in the 1970s [9] and, after three decades, diverse advances have taken place in an effort to develop ICT for the benefit of health. In Brazil, the HIS were developed by actors in both public and private sectors to meet the demands of health planning and management, as was the elaboration of a national strategic vision of heath informatics [4]. However, recent attempts by the Ministry of Health (MoH) aiming to construct an Electronic Health Record (EHR) on a national level failed and the HIS produced in Brazil are fragmented, limiting the use of the information for the benefit of the Brazilian population [8].

Considering the complex scenario related to the informatization of health in the Brazilian setting, it becomes necessary to study the factors associated with this process. Therefore, based upon the premise that participative actions can bring about better results for health ICTs, this work seeks to analyze the participation of diverse actors involved in the instances of discussions of health informatics in Brazil. 
To do so, this work articulates three theoretical perspectives - Health Information Systems Project [6-7, 10], Information and Information Technology in Health $[8-9,11]$, and Development Studies [12] - in order to formulate an analytical model that relates instances and actors involved in the discussion of health informatics in Brazil. Therefore, national instances of discussion about health ICTs are identified, as are the actors who have participated in such instances.

This work is organized in the following manner: After the introduction, section 2 reviews literature associated with the three theoretical perspectives cited and presents the analytical model for the analysis of participation in instances of discussion on health informatics. Section 3 discusses the methodological procedures adopted in the study. Section 4 presents the results accrued from the analysis of the chronological trajectory of health informatics in Brazil, from the 1990s onwards, and section 5 discusses the results found. Finally, in section 6, the work's conclusions are presented.

\section{Literature Review}

Since the 1990s, diverse countries have sought to explore the possibilities associated with health ICTs through national projects and strategies. Among such one can quote Canada [1], Australia [2] and England [3] and more recently the United States [5]. Such initiatives have generally been conducted by independent entities that support local actions aiming to develop HIS, while, on a national level, they seek to link governmental actors and civil society, in order to construct agreements and define patterns to integrating local systems.

Research shows that the social participation in discussion processes and implementation of health ICT can be a critical factor for the success of these projects. As such, in the following paragraphs three theoretical perspectives that study participatory processes will be presented: Health Information Systems Project [6-7, 10], Information and Information Technology in Health [8-9, 11] and Development Studies [12].

In the context of studies about ICT in developing countries, the Health Information Systems Project (HISP) [6-7, 10], observing the necessity to develop HIS in a sustainable and scalable manner [6-7], argues about the importance of establishing networks of action that make feasible the implementation of HIS $[6,10]$.

The networks of action [6 p. 342] are defined as "intended to capture the dynamics of translating, aligning heterogeneous networks of routines, technology, and learning within politically contested terrains of opposing projects and ideologies, in an effort to promote sustainable, replicable changes". This network of heterogeneous actors is mobilized to support the system, as well as promote the sustainability of HIS [6-7], scalability [6], technical capabilities, and learning [10]. The actors of networks of action include politicians, bureaucrats, representatives of international organizations, researchers, and technical artifacts, i.e. infrastructure, HIS and other technological resources. Therefore, strategies are needed to design flexible and participatory activities that bring together the different interests, with a view toward mobilizing support for HIS [6]. 
In Brazil, within the context of the Brazilian Sanitary Movement [8-9, 11], studies have argued how participative actions can enable the development of ICT, aiming at attending the interests of Brazilian society. For instance, Moraes and Vasconcellos [11 p. 97] put the challenge to "expand the use of information in the daily decision making of health, either in policy, management, surveillance, clinic or social control, facing unequal access to the benefits of technological advancement". Thus, they proposed a way to build a national pact around the theme of health informatics, suggesting the convening of a National Conference on Information and Information Technology in Health.

Moreover, Moraes and Gomez [8] proposed the construction of a politicalepistemological interfield encapsulating the production of information in health practices, from assistance to planning and management. In the words of the authors "an 'information and information technology 'interfield', in order to put forth a manifesto that considers actors, practices, procedures and knowledge that crosses over as well as penetrates other 'fields', have already constituted differentiated criteria of identity and value within common health references" [8 p. 560].

The information and information technology interfield accrued from the Brazilian Sanitary Movement integrates HIS, from assistance to planning and management. This interfield is composed of the entirety of information related to health, namely administrative, financial, and assistance, in both the domain of public and private health. Or in other words, information that is widely used, from clinical practice - in professional/patient relations - to planning and management actions [8].

Based on the concept of the information and information technology interfield, Moraes and Gomez [8] illustrate some spaces for discussion of the production of health information. These areas involve public and private actors, comprising: (a) the ways of life in health, regarding civil society; (b) the government, covering instances of integrative health information; (c) economic undertakings, encompassing the producers of goods and services of ICT; and (d) science and technology, including education and research in informatics in health. The spaces would be related and, through them, informational praxis in health would be discussed [8].

Finally, within the context of Development Studies, Evans [12] observes the frustrating results of the institutional monoculture, which as he explains, "try(ing) to impose uniform institutional blueprints on the countries of the South - what I call "institutional monocropping" - has produced disappointing results" [12 p. 20]. Therefore, the author proposes for the amplification of the notion of development to go beyond economic growth and, based in the thinking of Amartya Sen, defends the organizational move in which "'deliberative democracy" offers a more substantial institutionalization of "public discussion and exchange"” [12 p. 22].

Thus, Evans [12 p. 22] argues that, "institutions indeed appear to be effective in engaging the energies of ordinary citizens in the process of social choice', in that they "appear to increase citizenry's willingness to invest in public goods and to enhance the delivery of these goods".

Therefore, based on the contributions of the three perspectives cited above, this work defines an analytical model for analysis of participation in the instances of 
discussion on health informatics (Figure 1), composed by instances of discussion and actors.

The instances of discussion are defined as spaces in which actors discuss and deliberate questions related to health ICT. Therefore, they influence the development of material elements of health informatics, which are: HIS, patterns of interoperability and norms, such as the allocation of resources, finances, technologies and people. This definition is based on the concept of networks of action [6], interfield spaces of information and information technology in health [8], and deliberative institutions [12].

The actors are defined as representatives of diverse segments involved in health ICT. According to the three perspectives $[6,8,12]$, such actors are comprised of politicians, bureaucrats, businesses, social movements, international organisms, science and technology organizations, and class associations, among others. Based on Moraes and Gomez [8], the actors are classified in accordance with four categories: government, businesses, science and technology and civil society.

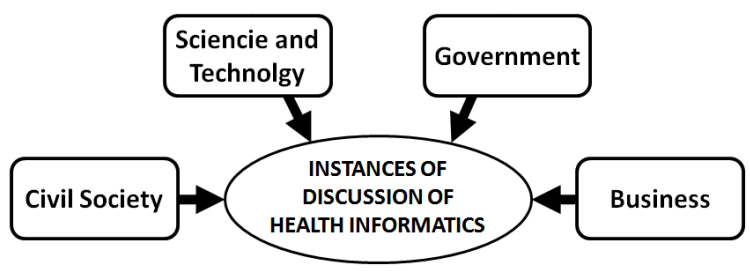

Fig. 1. Analytical model of participation in instances of discussion on health informatics

Stemming from the theoretical concepts proposed and based upon the premise that participative institutions can generate better results for public policies on health ICT in Brazil, this work seeks to identify how instances of discussion were instituted throughout the last twenty years, how they came about, which objectives they hold and which actors have participated in these instances.

Thus, the objective of this paper is to understand how instances of discussion on health informatics are promoting social participation in the formation and implementation of public policies in health informatics in Brazil.

\section{Method}

This study, aiming to analyze the instances of discussion related to health informatics, is based upon a qualitative approach supported by documental analysis. For such, as shown in Table 1, information about legislations and norms related to the Brazilian health system have been collected, more specifically regarding health informatics, from the 1980s onwards. It was also surveyed news and reports about actions related to the informatization of health in Brazil.

The analysis of the data is based upon the analytical model proposed in section 2 . Thus, actors and instances of discussion related to health information policies were analyzed via this aforementioned model. 
Table 1. Laws and norms associated with the institutionalization of health informatics in Brazil

\begin{tabular}{|l|l|}
\hline \multicolumn{1}{|c|}{ Law/Norm } & \multicolumn{1}{c|}{ Description } \\
\hline Federal Constitution of 1988 [13] & $\begin{array}{l}\text { Assures health as a social right and government } \\
\text { obligation. }\end{array}$ \\
\hline Law 8080/1990 [14] & Organic Law of Health. \\
\hline Law 8142/1990 [15] & Institutes participation at SUS. \\
\hline Decree 100/1991 [16] & Creates Datasus. \\
\hline Ordinance MoH 01/1996 [17] & Creates CIB and CIT. \\
\hline Resolution CNS 227/1998 [18] & Creates CICIS at CNS. \\
\hline Law 9782/1999 [19] & Creates Anvisa. \\
\hline Law 9961/2000 [20] & Creates ANS. \\
\hline Ordinance MoH 1919/2002 [21] & Creates RIPSA. \\
\hline Resolution CNS 349/2005 [22] & Reformulates CICIS. \\
\hline Ordinance ANS 19/2006 [23] & Creates COPISS at ANS. \\
\hline Ordinance MoH 349/2009 [24] & Creates CIINFO/MoH. \\
\hline Ordinance MoH 2072/2011 [25] & Reformulates CIINFO/MoH. \\
\hline Ordinance MoH 2073/2011 [26] & Regulates standards for information sharing at SUS. \\
\hline
\end{tabular}

The instances of discussion were identified as the spaces established in the legislation. During their analysis, one attempted to identify the goal set for each instance, and the period in which the instances were created (and, in some cases, altered). The actors include institutional participants in the instances of discussion, namely government, business, science and technology institutions, and civil society.

The following section presents a historical trajectory of health informatics in Brazil, showing its main events. Then, discussion section sought to identify how the objectives of instances of discussion complement each other or overlap. Furthermore, one attempted to analyze how the different categories of actors were present in each instance of discussion.

\section{$4 \quad$ Health ICT in Brazil}

In Brazil, the first HIS appeared in the 1970s in the welfare health system in effect at the time, and in the 1980s HIS were developed to control the billing submitted by health providers accredited by the National Institute of Social Security (INAMPS) [9].

In the 1980s, the Sanitary Movement, in order to challenge the prevailing model at the time, championed a political campaign for the universal right to health. This campaign was called the Brazilian Sanitary Reform, which culminated with the institution of the Unified Health System (SUS), the current base of the Brazilian health system [27]. 
The Brazilian health system, SUS, encompasses the universal right to health, public financing, administrative decentralization, and community participation. These fundaments have been achieved at Federal Constitution of 1988 [13], Law 8080 of 1990 [14], and Law 8142, also of 1990 [15]. Due to that, national, state and municipal councils on health were created, representing the instances of social participation in the discussions on the Brazilian health system [15], such as the Intergovernmental Commissions Tripartite (CIT) and the Intergovernmental Commissions Bipartite (CIB), which comprise the instances of interfederative pacts with the SUS [17].

Along with the SUS, the National Health Information System (NHIS) was established, whose organization fell to the Ministry of Health $(\mathrm{MoH})$, in partnership with states and municipalities. To account for this attribute, in 1990 the IT Department of SUS (Datasus) was created [16]. The decentralized management, a basic tenet of the SUS, oriented actions aiming to provide HIS at regional and local levels. As such, Datasus began to produce HIS to support the actions of state and municipal health secretariats.

Considering the range of existing HIS in Brazil and the necessity to homogenize information, the $\mathrm{MoH}$, at the end of the 1990s, launched the National Health Card project [11, 28-29]. This project aimed to create a national registry of citizens, and as such, aggregate the information present in various HIS used in Brazil, providing a platform to channel informatics around the EHR. However, few results have been effectively reached to date [28].

In the 2000s, regulatory agencies in the health arena were established: the National Regulatory Agency for Private Health Insurance and Plans (ANS) [20] and the Brazilian Health Surveillance Agency (Anvisa) [19]. The ANS introduced new governance in the management of supplementary health, regulating operating activities and private health service providers. Anvisa had already come to act within the National Health Surveillance System, regulating the commercialization of products and services subject to sanitary vigilance. Thus, agencies came to command informatics activities within their areas of expertise.

Still in the 2000s, the first mobilizations pursuing a more holistic view of health information began. These mobilizations culminated in 2004 with the publication of the National Policy on Information and Information Technology in Health (PNIIS) in the 12th National Health Conference [4]. The PNIIS, while being a trademark, became an important referential in the development of health informatics in Brazil, as it defined the national strategic vision. Thus, guidelines and actions designed and established responsibilities to government actors and civil society. However, since the publication of PNIIS, very little of its propositions have actually been implemented.

In 2002, the Inter-Agency Health Information Network (RIPSA) was created with the objective of consolidating the generation of health information, as agreed with the Pan American Health Organization (PAHO) [21]. During this period, the National Council of Health (CNS) also reformed the Intersectoral Commission of Health Communication and Information (CICIS), established in 1998 [18], which aims to assist the CNS in subjects seeking the democratization of communication and information [22]. 
Meanwhile, in 2004, ANS established the pattern of Private Health Insurance Plans and Information Exchange Standard (TISS), which allowed electronic information exchanges between providers and operators in private health. Aiming to continue to TISS and other actions in the private health, in 2006, ANS established the Private Health Insurance Plans and Information Standardization Committee (COPISS), in order to promote the development of electronic information exchange in private health [23].

Alongside the activities of the MoH, the Brazilian Society of Health ICT (SBIS), in conjunction with the Federal Council of Medicine (CFM), has developed a certification process for EHR. This process, also known as electronic signature, became a significant milestone in health ICT, as it established the legal foundation for the full adoption of computerized clinical record as a substitute to paper.

More recently, in 2009, the MoH established the Health Information and Information Technology Committee $(\mathrm{CIINFO} / \mathrm{MoH})$ with regulatory functions, policies and oversight of the activities of health informatics within the SUS [25]. In 2011, the $\mathrm{MoH}$, based on the determination of the CIINFO, regulated standards for interoperability of health information [26]. This discussion did not count on the participation of other actors of civil society, who strongly criticized the actions of the $\mathrm{MoH}$ [30].

In parallel, fragmented HIS continued to be developed. The $\mathrm{MoH}$, itself, currently owns around 60 information systems, which support various administrative functions, assistance and statistics [31], while states and municipalities use more than 700 HIS [28]. Furthermore, in the supplementary health sector, HIS have been developed aiming at an efficient management of inventories and costs.

From the scenario presented, the next section unveils the actors and instances of discussion of health informatics in Brazil, arguing some implications accrued from these instances in the outcomes of health informatics in Brazil.

\section{Discussion}

Participation is present in the discourse of health information in Brazil since the rise of the SUS, as the Brazilian constitution assures society's participation in actions related to health [13]. Likewise, social participation is assured in instances of health planning and management, as is the case of national, state and municipal councils on health [15].

In the case of health informatics, some instances of participation have their thematic spaces, such as the CICIS within the CNS [18, 22], the COPISS within the ANS [23], and CIINFO within MoH . The text of PNIIS also reinforces the importance of participatory activities for the determination of actions on health informatics [4].

Although the participatory instances have existed since the beginning of the SUS, in recent years there is increasing discussion of instances of health informatics, as was the case with RIPSA [21], COPISS [23] and CIINFO [24, 30]. These instances reflect the complexity of the Brazilian health system, which receives public and private financing, as well as the participation of both public and private health service providers. 
The complexity of the health informatics scenario is evidenced by the wide range of state actors and civil society organizations present in the discussion of public policy related to the area. In public health, there are SUS managers $-\mathrm{MoH}$, state health departments and local health departments - public providers of health services and social control agencies, such as the CNS, state boards and municipal councils health. In supplementary health, ANS, health insurance companies and private providers are present. There are also actors who are part of both the public and supplementary health system, namely: the citizenry, philanthropic providers, associations, institutions of science and technology, and service providers of healthcare information technology.

These actors have debated health informatics in various stages of discussion, as presented in Table 2. As it can be seen, it was found via consultation with the current legislation four instances of discussion about health informatics without a single coordination or assignment of tasks, which can create conflicts that might affect the advancement of health informatics public policy in Brazil.

Table 2. Instances of discussion of health informatics

\begin{tabular}{|c|c|l|}
\hline $\begin{array}{c}\text { Instance of } \\
\text { Discussion }\end{array}$ & Year & \multicolumn{1}{|c|}{ Description } \\
\hline CICIS & 1998 & $\begin{array}{l}\text { Support CNS in questions regarding information and } \\
\text { information technology in health. }\end{array}$ \\
\hline RIPSA & 2002 & Improve usage of information in health. \\
\hline COPISS & 2006 & $\begin{array}{l}\text { Promote development and improvement of information } \\
\text { exchange in private health. }\end{array}$ \\
\hline CIINFO & 2009 & $\begin{array}{l}\text { Normative, regulatory and supervisory functions of health } \\
\text { ICT in the SUS. }\end{array}$ \\
\hline
\end{tabular}

As for the actors present in this discussion, CICIS is represented by members of government and civil society; RIPSA includes actors within the $\mathrm{MoH}$ and technicalscientific institutions, the COPISS comprises a wide range of government and civil society, and finally the CIINFO considers organs of the $\mathrm{MoH}$, Ministry of Planning, RIPSA and ABNT. As shown in Table 3, the actors from government, civil society, business and science \& technology are present to a greater or lesser degree, in various instances of discussion.

The COPISS consists of various actors in society. Although it has an over representation of civil society and an under-representation of businesses, COPISS is constituted in a plural forum involving various actors of supplementary health in its principal context of discussion.

However, some instances contain mostly government officials, as the CIINFO, which consists mainly of actors from government itself. Moreover, it can still be observed in some instances, as CICIS and COPISS, that important government actors, although having a seat, have not indicated representatives yet. Finally, the low level of participation of businesses in instances of discussion is also noted. 
Table 3. Number of actors present in instances of discussion

\begin{tabular}{|c|c|c|c|c|}
\hline $\begin{array}{c}\text { Instance of } \\
\text { Discussion }\end{array}$ & Government & Civil Society & $\begin{array}{c}\text { Science and } \\
\text { Technology }\end{array}$ & Business \\
\hline RIPSA & 7 & - & 1 & - \\
\hline CIINFO & 12 & 1 & 2 & - \\
\hline CICIS & 3 & 12 & 1 & - \\
\hline COPISS & 3 & 16 & 1 & 2 \\
\hline
\end{tabular}

The asymmetries of participation can influence the participatory debate on the formulation and implementation of health informatics public policy in Brazil. According to Evans [12], institutions with social participation increase the likelihood of generating public goods and societal engagement in public policy. Likewise, Moraes and Gomez [8] proposes the reconstruction of an interfield of information and informatics in health, involving various segments of society. Thus, Braa et al. [6] advocate the construction of networks of action involving diverse community actors in the implementation of HIS. It is necessary that the government and civil society actors are represented in the various spheres of discussion, in order to build intertemporal agreements that lead to the development of information technology in this field.

Actions without the broad participation of society can lead to conflicts, as is the case of the ordinance that regulates the exchange of information between information systems used in the public and private spheres [26]. Such regulation has suffered various criticisms for not considering the interests of civil society [30].

On the other hand, the case of ANS represents a breakthrough in discussions with government and civil society. The agency has developed TISS and TUSS standards allowing the automation of transactions between health providers and health operators, increasing the adoption of ICT for private health.

Finally, other actors, even without much government involvement, have developed actions. An example is the digital certification standard for EHR, prepared by SBIS in conjunction with CFM, without the participation of MoH. Thus, one observes that actions, even without the direct participation of government representatives, set standards in health ICT that ended up being used all over the country.

\section{Concluding Remarks}

Health ICTs have been part of the Brazilian scenario since the 1970s, but today they still have not been able to transform health practices in the country. While there have been advances in the area, limitations in the effective use of informatics within health practices in Brazil still exist.

Recent failures in the construction of EHR reveal instances in which the process of health informatization will not take place by itself. Rather, a discussion that includes the government, businesses and civil society becomes necessary, aiming to develop health informatics toward the benefit of Brazilian society. 
Participation is present in the discourse of health information since the surge of the SUS but in recent years an increase in instances of discussion has been observed. These new instances reflect the intention of actors to create spaces to influence health informatization. It is important that these instances possess particular coordination and attributions, in order to avoid conflicts in the standardization and definitions produced in each space.

It is also important that the instances of discussion have representation from diverse actors from both the government and civil society, thus producing agreements that engage all participants in the construction of public goods that convey to the development of health informatics.

This study focused on the Brazilian scenario, not analyzing local or regional experiences. Future research may be based on the proposed theoretical framework to analyze other instances of discussion.

Furthermore, the categories employed in this study can also limit the understanding of the complexity of actors involved in the discussion of health informatics in Brazil. For example, Brazilian civil society is not homogeneous, representing diverse and quite often divergent interests. Thus, more studies become necessary in order to better understand the interests present within Brazilian health informatics.

The enlargement of theoretical backgrounds is a highly argued topic within studies about ICT in developing countries. Avgerou [32] observes that, "we need studies of the political actors and institutions through which economic models and technological potential are translated into industries, information infrastructures and 'empowered' societies". This work points in that direction, toward the proposal of an integration of three theoretical perspectives for better understanding the HIS in Brazil.

Finally, it is expected that the perspective proposed in this work enable the development of further studies that seek to assess the quality of public policies, norms and definitions produced in instances of discussion, as well as the social participation that these instances provide.

\section{References}

1. Alvarez, R.C.: The promise of e-Health - a Canadian perspective. Ehealth International 1, 4 (2002)

2. Gunter, T., Terry, N.: The Emergence of National Electronic Health Record Architectures in the United States and Australia: Models, Costs, and Questions. Journal of medical Internet Research 7 (2006)

3. Bowns, I., Rotherham, G., Paisley, S.: Factors associated with success in the implementation of information management and technology in the NHS. Health Informatics Journal 5, 136-145 (1999)

4. Brasil. Ministry of Health: A construção da política nacional de informação e informática em saúde: proposta versão 2.0, 40 (2004)

5. Blumental, D.: Stimulating the Adoption of Health Information Technology. The New England Journal of Medicine 360, 1477-1479 (2009)

6. Braa, J., Monteiro, E., Sahay, S.: Networks of Action Sustainable Health Information Systems Across Developing Countries. MIS Quarterly 28, 337-362 (2004)

7. Kimaro, H.C., Nhampossa, J.L.: The challenges of sustainability of health information systems in developing countries: comparative case studies of Mozambique and Tanzania. Journal of Health Informatics in Developing Countries 1, 1-10 (2007) 
8. Moraes, I.H.S., Gomez, M.N.G.: Informação e informática em saúde: caleidoscópio contemporâneo da saúde. Ciência \& Saúde Coletiva 12, 553-565 (2007)

9. Moraes, I.: Informações em Saúde: da Prática Fragmentada ao Exercício da Cidadania. Abrasco, São Paulo e Rio de Janeiro (1994)

10. Sheikh, Y., Braa, K.: Mobilising Local Networks of Implementers to Address Health Information Systems Sustainability. Electronic Journal on Information Systems in Developing Countries 48, 1-21 (2011)

11. Moraes, I.H.S., Vasconcellos, M.M.: Política Nacional de Informação, Informática e Comunicação em Saúde: um pacto a ser construído. Saúde em Debate 29, 86-98 (2005)

12. Evans, P.: Além da "Monocultura Institucional": instituições, capacidades e o desenvolvimento deliberativo. Sociologias 5, 20-63 (2003)

13. Brasil: Federal Constitution of 1988. Congress Press, Brasília (1988)

14. Brasil: Law n. 8080. Federal Official Gazette of Brazil, Brasília (1990)

15. Brasil: Law n. 8142. Federal Official Gazette of Brazil, Brasília (1990)

16. Brasil: Decree n. 100. Federal Official Gazette of Brazil, Brasília (1991)

17. Brasil. Ministry of Health: Ordinance n. 2203 Federal Official Gazette of Brazil, Brasília (1996)

18. Brasil. National Concil of Health: Resolution n. 277 Federal Official Gazette of Brazil, Brasília (1998)

19. Brasil: Law n. 9782. Federal Official Gazette of Brazil, Brasília (1999)

20. Brasil: Law n. 9961. Federal Official Gazette of Brazil, Brasília (2000)

21. Brasil. Ministry of Health: Ordinance n. 1919. Federal Official Gazette of Brazil, Brasília (2002)

22. Brasil. National Concil of Health: Resolution n. 349 Federal Official Gazette of Brazil, Brasilia (2005)

23. Brasil. National Regulatory Agency for Private Health Insurance and Plans. Directory of Sectorial Development: Normative Instruction n. 19. Federal Official Gazette of Brazil, Brasília (2006)

24. Brasil. Ministry of Health: Ordinance n. 327. Federal Official Gazette of Brazil, Brasília (2009)

25. Brasil. Ministry of Health: Ordinance n. 2072. Federal Official Gazette of Brazil, Brasília (2011)

26. Brasil. Ministry of Health: Ordinance n. 2073. Federal Official Gazette of Brazil, Brasília (2011)

27. Brasil. Ministry of Health. Secretaria de Gestão Estratégica e Participativa: A construção do SUS: histórias da Reforma Sanitária e do Processo Participativo. Ministério da Saúde, Brasília (2006)

28. Brasil. National Council of Health Secretaries: Ciência e Tecnologia em Saúde, v. 11. CONASS (2011)

29. Cunha, R.E.: Cartão Nacional de Saúde: os desafios da concepção e implantação de um sistema nacional de captura de informações de atendimento em saúde. Ciencia \& Saude Coletiva 7, 869-878 (2002)

30. Brasil. Ministry of Health. Executive Secretariat. Datasus: Public Consulting of Unified Health System, Brasília (2011)

31. Brasil. Ministry of Health: Plano Diretor de Tecnologia da Informação 2010-2013. Plano Diretor de Tecnologia da Informação 2010-2013 (2010)

32. Avgerou, C.: Discourses on ICT and development. Information Technologies and International Development 6, 1-18 (2010) 


\section{Glossary}

\begin{tabular}{|l|l|}
\hline ANS & National Regulatory Agency for Private Health Insurance and Plans \\
\hline Anvisa & Brazilian Health Surveillance Agency \\
\hline CFM & Federal Council of Medicine \\
\hline CIB & Intergovernmental Commissions Bipartite \\
\hline CICIS & Intersectorial Commission of Health Communication and Information \\
\hline CIINO & Information and Information Technology in Health Committee \\
\hline CIT & Intergovernmental Commission Tripartite \\
\hline CNS & National Council of Health \\
\hline COPISS & Private Health Insurance and Plans Information Standardization Committee \\
\hline Datasus & IT Department of SUS \\
\hline HER & Electronic Health Record \\
\hline HIS & Health Information Systems \\
\hline ICT & Information and Communication Technologies \\
\hline MoH & Ministry of Heath \\
\hline PAHO & Pan-American Health Organization \\
\hline PNIIS & National Policy on Information and Information Technology in Health \\
\hline RIPSA & Inter-Agency Health Information Network \\
\hline SBIS & Brazilian Society of Health ICT \\
\hline SNIS & National Health Information System \\
\hline SNVS & National Health Surveillance System \\
\hline SUS & Unified Health System \\
\hline TISS & Private Health Insurance and Plans Information Exchange Standard \\
\hline
\end{tabular}

